
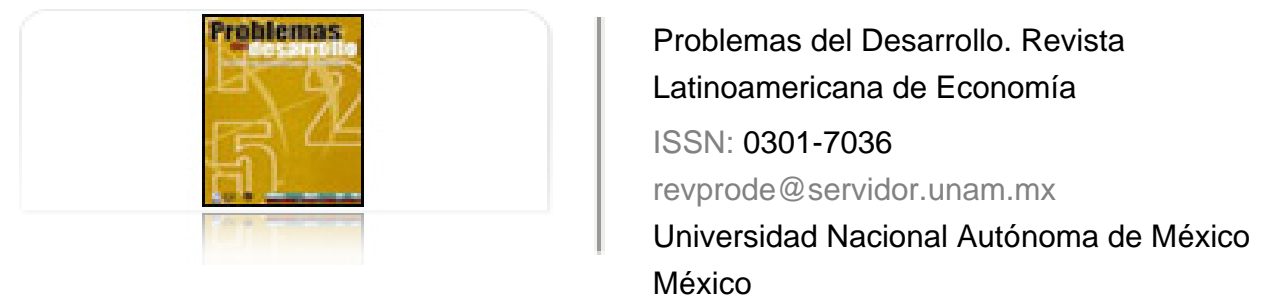

Ramírez Alcocer, Lorena; Schwentesius Rindermann, Rita; Gómez Cruz, Manuel Ángel; Martínez Borrego, Estela La organización de productores y los programas de comercialización del Sorgo en Guanajuato (México)

Problemas del Desarrollo. Revista Latinoamericana de Economía, vol. 37, núm. 145, abril-junio, 2006, pp. $177-201$

Universidad Nacional Autónoma de México

Distrito Federal, México 


\title{
LA ORGANIZACIÓN DE PRODUCTORES Y LOS PROGRAMAS DE comercialización del sorgo en Guanajuato (MÉxico)
}

\author{
Lorena Ramírez Alcocer* \\ Rita Schwentesius Rindermann** \\ Manuel Ángel Gómez Cruz *** \\ Estela Martínez Borrego****
}

Fecha de recepción: 25 de agosto de 2005. Fecha de aceptación: 6 de mayo de 2006.

\section{Resumen}

Se analizan las organizaciones de productores de sorgo del estado de Guanajuato y el acceso de éstas a los programas de apoyo orientados a la comercialización del grano. Para ello, se aplicaron entrevistas abiertas a productores, a representantes de organizaciones y a funcionarios de los distintos niveles de gobierno. $89 \%$ de las organizaciones estudiadas tienen al menos catorce años de antigüedad, se integran en promedio con 62 productores y su actividad está orientada fundamentalmente a la comercialización de granos, la gestión de crédito y la captación de los apoyos federales para la comercialización. Se concluye que las organizaciones bajo estudio tienen dificultades para acceder a los apoyos a la comercialización, debido a que son pequeñas, con baja capacidad de almacenaje y de acceso limitado al financiamiento.

Palabras clave: ASERCA, organización de productores, sorgo.

* Alumna del doctorado del Centro de Investigaciones Económicas y Tecnológicas de la Agricultura Mundial (CIESTAAM) de la Universidad Autónoma Chapingo. Correo electrónico: 1ra02@hotmail.com

* Profesora-investigadora del doctorado en Problemas Económicos Agroindustriales, y Coordinadora del PIAI-CIESTAAM. Correo electrónico: rsr@avantel.net.

*** Profesor investigador del doctorado en Problemas Económicos Agroindustriales, CIESTAAM. Correo electrónico: ciestaam@avantel.net.

**** Profesora -investigadora del Instituto de Investigaciones Sociales de la Universidad Nacional Autónoma de México. Correo electrónico: mborrego@servidor.unam.mx 


\section{Abstract}

This paper analyzes sorghum producers' organizations in the state of Guanajuato and their access to support programs oriented towards the sale of grain. For this purpose, open interviews were carried out with producers, representatives of organizations and officials at different levels of government. 89\% of the organizations studied have been going for at least fourteen years, are made up of an average of 62 producers and their activity is oriented fundamentally to the sale of grain, credit management and obtaining federal sales support. It is concluded that the organizations under study have difficulties obtaining sales support, because they are small, have low storage capacity and limited access to financing.

Key words: ASERCA, producers' organization, sorghum.

\section{Résumé}

On y analyse les organisations des producteurs de sorgho de l'état de Guanajuato et l'accès de celles-ci aux programmes de soutien orientés à la commercialisation des graines. Dans ce but, on a appliqué des interviews ouvertes aux producteurs, aux représentants d'organisations et aux fonctionnaires des différents niveaux du gouvernement. 89\% des organisations étudiées ont au moins quatorze ans d'ancienneté, elles sont formées en moyenne par 62 producteurs et leur activité est fondamentalement orientée vers la commercialisation des graines, la gestion de crédit et la captation des aides fédérales pour la commercialisation. On conclut que les organisations étudiées ont des difficultés pour accéder aux aides à la commercialisation étant donné qu'elles sont petites, ayant une petite capacité de stockage et un accès limité au financement.

Mots-cléfs: ASERCA, organisation de producteurs, sorgho.

\section{Resumo}

Analizam-se as organizações de produtores de sorgo do estado de Guanajuato e o acesso de tais aos programas de apoio orientados à comercialização do grão. Para tal efeito, aplicaram-se entrevistas abertas a produtores, a representantes de organizações e a funcionários dos diferentes níveis do Governo. O 89\% das organizações estudadas tem pelo menos catorze anos de antigüedade, integram-se em promédio com 62 produtores e sua atividade está orientada principalmente à comercialização de grãos, a gestão de crédito e a captação dos apoios federais para a comercialização. Conclui-se que as organizações sob estudo apresentam dificuldades para acederem aos apoios à comercialização por serem pequenas, com baixa capacidade de armazenagem e de limitado acesso ao financiamento.

Palavras chave: ASERCA, organização de produtores de sorgo.

\section{DeSarrollo}




\section{Introducción}

a comercialización de granos y oleaginosas en México estuvo regulada por el

Estado por más de cincuenta años. A partir de la adopción del modelo neoliberal,

la política cambió. Las empresas paraestatales relacionadas con el proceso de comercialización fueron vendidas o retiradas gradualmente del mercado. Así, la Comisión Nacional de Subsistencias Populares (CONASUPO) deja gradualmente de funcionar con el retiro de la compra de granos en 1985 y la eliminación de la mayoría de los precios de garantía en 1989 (con excepción de maíz y frijol). Finalmente, conasupo desaparece en 1999, a pesar de haber sido el principal comercializador de granos en el país. En este contexto se crea en 1991 el órgano desconcentrado de la Secretaría de Agricultura, Ganadería y Desarrollo Rural (SAGAR) denominado Apoyos y Servicios a la Comercialización Agropecuaria (ASERCA), con la finalidad de acelerar la modernización productiva del sector, identificar y, en su caso, crear los instrumentos necesarios para que, luego de un periodo de transición, las organizaciones de productores y agentes del sector privado puedan comercializar la cosecha nacional en forma eficiente (ASERCA, 2004: 8). Con el impulso de aserca, las organizaciones de productores orientadas a la comercialización de granos toman un papel relevante en su área de acción y en el otorgamiento de apoyos de los programas desarrollados por aserca.

México se ubica dentro de los principales países productores e importadores de sorgo. Sus Tasas de Crecimiento Media Anual (тсмA) de producción y de importación fueron respectivamente de $7.91 \%$ y $11.22 \%$ para el periodo $1961-2005$. El porcentaje de las importaciones ha aumentado de $5.40 \%$ en los años sesenta a $61.25 \%$ en 2005 . Así, el coeficiente de dependencia se incrementó de $11.39 \%$ en 1961 a $35.87 \%$ en 2005 . Esta tendencia se acentuó después de entrar en vigor el Tratado de Libre Comercio de América del Norte (TLCAN), que ha hecho de México un país netamente importador, y de Estados Unidos su principal proveedor.

Guanajuato es el segundo estado productor de sorgo del país y en los últimos 10 años ha aportado, en promedio, $25 \%$ de la producción nacional. Sin embargo, esta situación no tiene relación directa con su participación en los programas de apoyo otorgados a la comercialización de ASERCA. Por ejemplo, en el periodo 2002-2003 sólo recibió 2.13\% y $2.31 \%$ del total de apoyos; para el 2003, del total de los apoyos correspondientes al sorgo sólo participó con $0.09 \%$, mientras que Tamaulipas recibió 97.00\%, Nuevo León 2 \% y Sinaloa $0.90 \%$ (ASERCA, 2003). Ante esta situación de tan marcada disparidad en la canalización de los apoyos a la comercialización del sorgo, este trabajo establece los

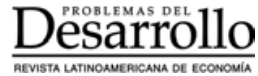


siguientes objetivos: a) elaborar un marco referencial de la situación y perspectivas del sistema productivo del sorgo en México; b) estudiar la estructura actual de comercialización de sorgo en Guanajuato y la importancia en ella de las organizaciones de productores rurales; c) conocer los programas de comercialización de sorgo en Guanajuato, y d) proponer lineamientos generales para el desarrollo de la comercialización del grano.

En este contexto, el trabajo pretende contribuir al conocimiento y análisis de las organizaciones de productores de sorgo y describir cómo éstas acceden al canal de comercialización y a los apoyos del gobierno federal destinados a esta fase de la cadena productiva en Guanajuato. La tesis central de la investigación considera que las características de la organización y la producción de sorgo en el estado de Guanajuato limitan el acceso de los productores a los programas de apoyo a la comercialización, dada la forma en que dichos programas han sido planteados por ASERCA.

Como parte de la metodología, se realizó una revisión de bibliografía e información disponible tanto en medios impresos como electrónicos; utilizando herramientas estadísticas y económicas. Se elaboró un conjunto de indicadores económicos considerando sistemas de graficación, consulta de sistemas de bases de datos e información geográfica, a la vez que se aplicaron entrevistas a agentes clave en la producción y comercialización de sorgo (representantes de organizaciones de productores y de instituciones a nivel estatal y nacional). Las entrevistas se aplicaron a habitantes de Guanajuato: cinco representantes de organizaciones de productores de Guanajuato (los cuales fueron seleccionados de forma aleatoria de un padrón de 18 organizaciones existentes), cinco productores de sorgo, dos integrantes de la Secretaria de Desarrollo Rural estatal, dos funcionarios de ASERCAGuanajuato, tres representantes de ASERCA sede nacional y un representante de Servicios Integrales de Almacenamiento y Comercialización de México (SIACOMEX).

\section{Marco de referencia}

En los últimos veinte años se pueden distinguir dos grandes periodos en la comercialización de granos en México. ${ }^{1}$ El primero, hasta 1988, tuvo como base una política de precios de garantía en un esquema de economía cerrada, donde los principales cultivos de granos y oleaginosas tenían precios de garantía y existían empresas paraestatales como coNASUPO y

1 El decenio de los ochenta estuvo marcado por el surgimiento de la ideología neoliberal, que se caracteriza por una amplia apertura comercial, desregulación financiera, establecimiento de derechos de propiedad y disminución de subsidios; así, las políticas de los países más poderosos se orientaron a la desregulación de mercados, la privatización de ciertas empresas y aumento de la competitividad internacional, mientras presionaron en el mismo sentido a los países subdesarrollados a través de las instituciones internacionales tales como el Fondo Monetario Internacional (FMI), el Banco Mundial (вM) y la Organización Mundial de Comercio (OMC, antes Acuerdo General sobre Aranceles y Comercio, GATT), que son las que fijan las reglas del comportamiento económico internacional a través de la "ayuda exterior" (Martínez et al., 2003:14). Fue en este marco donde se diseñaron las políticas para el sector agropecuario de México.

\section{DeSarrollo}


Bodegas Rurales CONASUPO (BUROCONSA), que eran prácticamente las encargadas de comprar, acopiar, financiar, almacenar y comercializar los granos. En 1989 se eliminó la mayor parte de los precios de garantía; esto obedeció a los compromisos que asumiera México en los acuerdos internacionales.

El segundo periodo está marcado por la adopción del modelo neoliberal, el cual tiene como eje principal la liberación de mercados y la venta de empresas paraestatales a la iniciativa privada. En este marco se desintegra la CONASUPO en 1999 — poco después de que BUROCONSA se transfiere a empresas privadas, ejidos y organizaciones de productores en 1996- a la vez que se instrumenta, entre otras medidas, una política de subsidios directos al ingreso de los productores. El final de conASUPO como el principal ente comercializador provocó un vacío que afectó a todos los agentes del campo. Ante esta situación, se había establecido un mecanismo de transición ${ }^{2}$ con la creación de ASERCA en 1991, con la finalidad de acelerar la modernización productiva del sector e identificar y, en su caso, crear los instrumentos necesarios para que, luego de un periodo de transición, las organizaciones de productores y agentes del sector privado pudieran comercializar la cosecha en forma eficiente. ASERCA debía también atender la conveniencia de establecer las directrices generales de comercialización en función de la creciente interrelación con el exterior (ASERCA, 2003). ASERCA opera principalmente los programas de apoyo a la comercialización en los estados con excedentes de producción en granos y tiene incidencia en las organizaciones de productores impulsadas por ella.

En un inicio, la política de comercialización de ASERCA se basó en un esquema de apoyos fiscales, mediante el llamado precio de indiferencia, política que consistía en proporcionar al comprador de granos nacionales un apoyo fiscal temporal que fuera equivalente al menor costo en que éste incurriera por adquirir cosechas nacionales en vez de cosechas importadas (Claridades Agropecuarias, 1994:4-5). El objetivo principal era otorgar subsidios a los grandes consumidores para que pagaran el producto nacional al mismo precio del grano importado (Steffen y Echánove, 2003:126). Esta política se estableció durante el periodo 1991-2000 y se caracterizó por su condición temporal y selectiva por regiones, productos y cosechas. A partir del 2001, el programa de apoyos a la comercialización y desarrollo de mercados regionales se orientó a la entrega de apoyos directos al productor (Claridades Agropecuarias, 2003:32).

2 Así, el 16 de abril de 1991 se publicó en el Diario Oficial de la Federación el Decreto que crea Apoyos y Servicios a la Comercialización Agropecuaria (ASERCA). Entre sus atribuciones se distingue: fomentar la organización de productores para la comercialización y su capacitación; fomentar la construcción de infraestructura básica para realizar eficientemente los procesos de comercialización; promover líneas de crédito en el sistema financiero para apoyar la comercialización y operar y supervisar programas temporales de apoyo a productores agropecuarios para hacer más fluida la comercialización de sus productos, entre otras (ASERCA, 2004:9 10). 


\section{La política de apoyo a la comercialización}

A partir de 2001 se desarrolló una política de comercialización integral que combina apoyos directos al productor y de instrumentos para manejar riesgos (cobertura de precios), promoción de exportaciones e información comercial y de comportamiento de los mercados (ASERCA, 2004: 16). Dentro de sus funciones, ASERCA debe llevar el registro del padrón de productores, la inscripción de los posibles acreedores de apoyo, verificar que sus expedientes estén completos y cumplan con todos los requisitos, además de entregar subsidios.

Para el ejercicio fiscal 2003, ASERCA instrumentó un nuevo esquema de apoyos, que opera a través del programa de apoyos directos al productor por excedentes de comercialización para reconversión productiva, integración de cadenas agroalimentarias y atención a factores críticos, donde destacan por su innovación, los subprogramas siguientes: Apoyos Directos al Ingreso Objetivo; Apoyos Directos a Pignoración; Apoyos Directos para la Conversión de Cultivos; Apoyos para la Adquisición de Coberturas de Precios Agropecuarios, y otros Esquemas de Apoyos, donde se despliegan los apoyos directos al acceso de granos forrajeros nacionales, apoyos a la exportación y/o cabotaje, no flete terrestre, apoyos para la agricultura por contrato y apoyos al productor para la atención a factores críticos de comercialización (ASERCA, 2004: 17).

\section{Organización de productores}

El principal sostén para la construcción del corporativismo en el campo mexicano fue el reparto agrario, tanto en el sector social (ejido y comunal) como en el sector de la pequeña propiedad (de Grammont, 1996: 10). Desde el triunfo de la revolución mexicana, cualquier forma de organización económica en el medio rural era promovida por el gobierno con el propósito de poder utilizarla como vía para la consolidación del régimen corporativo y clientelar, y para facilitar la ejecución de los programas oficiales (Gordillo et al., 1999). Con el proceso del retiro estatal de la actividad agropecuaria, la eliminación de la política compensatoria y la apertura comercial se obliga a los productores agrícolas, campesinos y empresarios a generar alternativas nuevas. Una de las opciones fue la creación de empresas de productores generadoras de servicios (Flores, 2003: 159).

Las organizaciones rurales son relativamente recientes. De las 673 que integraron el Programa de Fomento a Empresas Comercializadoras Agropecuarias del Sector Social (PROFECA) 78\% se crearon en el periodo 1991-2000. Este indicador parece sugerir que en la medida en que el Estado fue cancelando o transfiriendo sus operaciones comerciales y financieras a través de la privatización, el cierre de empresas e instituciones públicas, fueron surgiendo organizaciones que empezaron a ocupar los espacios abandonados por él. De esta forma, diversos grupos de productores rurales se han constituido en Sociedades 
de Producción Rural (SPR), Sociedad de Interés Colectivo y Unión de Sociedades de Productores Rurales (USPR), principalmente (Muñoz y Flores, 2004: 48).

De acuerdo con la Organización de las Naciones Unidas para la agricultura y la alimentación (FAO) (1995) y Ayala (1999), las organizaciones se diseñan para maximizar los beneficios y utilidades y surgen porque es necesario repartir los costos asociados a la gestión del intercambio y al logro de economías de escala. Muñoz et al. (2004) indican siete principios implícitos en las organizaciones que hacen viable el surgimiento y consolidación de un tipo de empresa que gradualmente se ha ido multiplicando en todas las actividades económicas hasta formar toda una red de cooperativas que son parte de un sistema económico y empresarial nuevo. Tales principios son: adhesión voluntaria y abierta; gestión democrática por parte de los socios; participación económica de los socios; autonomía e independencia; educación, formación e información; cooperación entre cooperativas, e interés por la comunidad.

\section{El sorgo en el contexto actual}

En el ciclo 2003-2004, México figuró entre los principales países productores de sorgo, aportando 10.4\% (5.6 millones de toneladas) del total mundial producido, después de Estados Unidos, India y Nigeria; en cuanto a consumo, se ubica en el segundo lugar, con 14.4\% (9.3 millones de toneladas); respecto a las importaciones, se sitúa como el principal importador de sorgo a nivel mundial, con $47.8 \%$ (3.1 millones de toneladas), siendo su principal proveedor Estados Unidos (USDA/FAS: 2006). La importancia del sorgo en México radica en que es fuente de materia prima para la industria de alimentos balanceados para animales: en ganado bovino, constituye 30\% del consumo diario; en porcino, 65\%; en caprino, $50 \%$, en ovino, $50 \%$, y en aves, $65 \%$ (CANACINTRA, 2002), lo que a su vez permite que en el mercado alimentario para personas se disponga de proteínas de origen animal.

Las expectativas de que México deje de ser deficitario en sorgo son bajas, dado que el consumo se ha incrementado considerablemente desde finales de los setenta por el crecimiento de los procesos de ganaderización (Barkin et al., 1991: 55); no obstante que la producción de sorgo ha aumentado, no ha sido en la misma proporción que el consumo, por lo que las importaciones han mostrado una tasa de crecimiento media anual (TCMA) de $11.22 \%$ en el periodo 1961-2005, en comparación con la de producción, que fue de $7.91 \%$, y con la de consumo, de $8.70 \%$ (Gráfica 1).

De ser un país autosuficiente e incluso exportador neto de sorgo durante los años 1968 a 1971, México se convierte en un importador neto a fines de los años 70 (Gráfica 2). Con ello el coeficiente de dependencia se incrementó: en 1961 fue de $11.39 \%$, en 1981 de $61.40 \%$, en 1991 de $44.32 \%$, y en 2005 de $35.87 \%$, lo que ubica a México cómo un país dependiente de las importaciones de sorgo. Durante los años del TLCAN la dependencia de la importaciones equivale a $37 \%$.

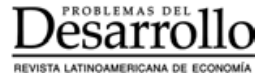




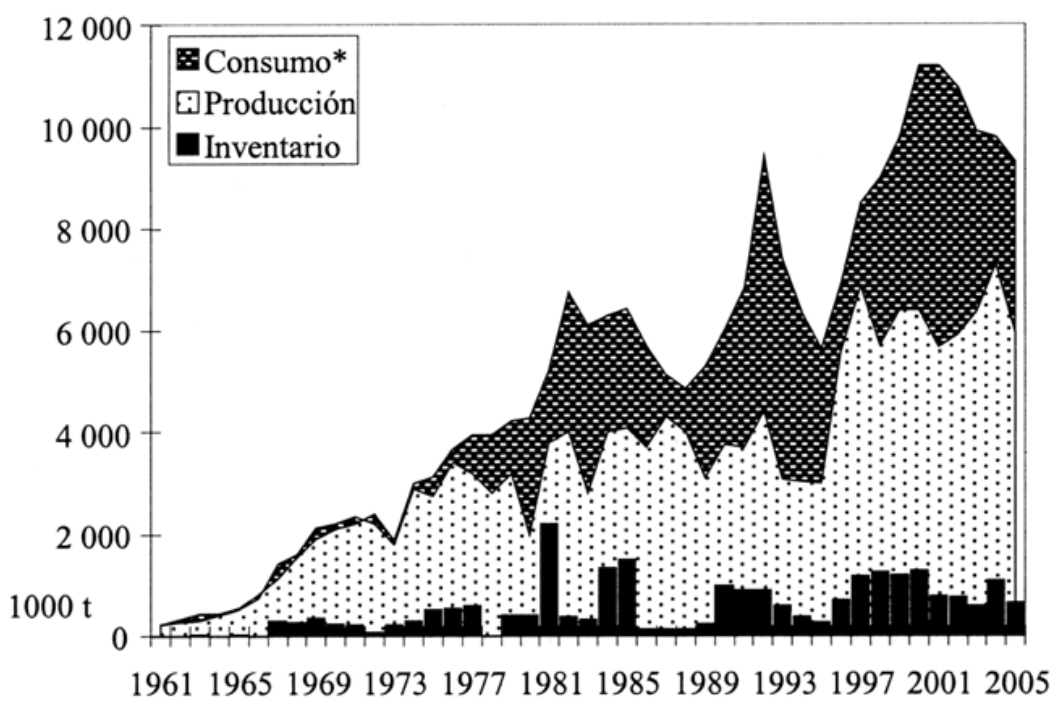

Gráfica 1. México. Consumo, producción, e inventarios de sorgo, 1961-2005 (1 000 toneladas)

* Consumo $=$ Producción+Importación-Exportación.

Fuente: elaboración propia con base en USDA/FAS, 2006.

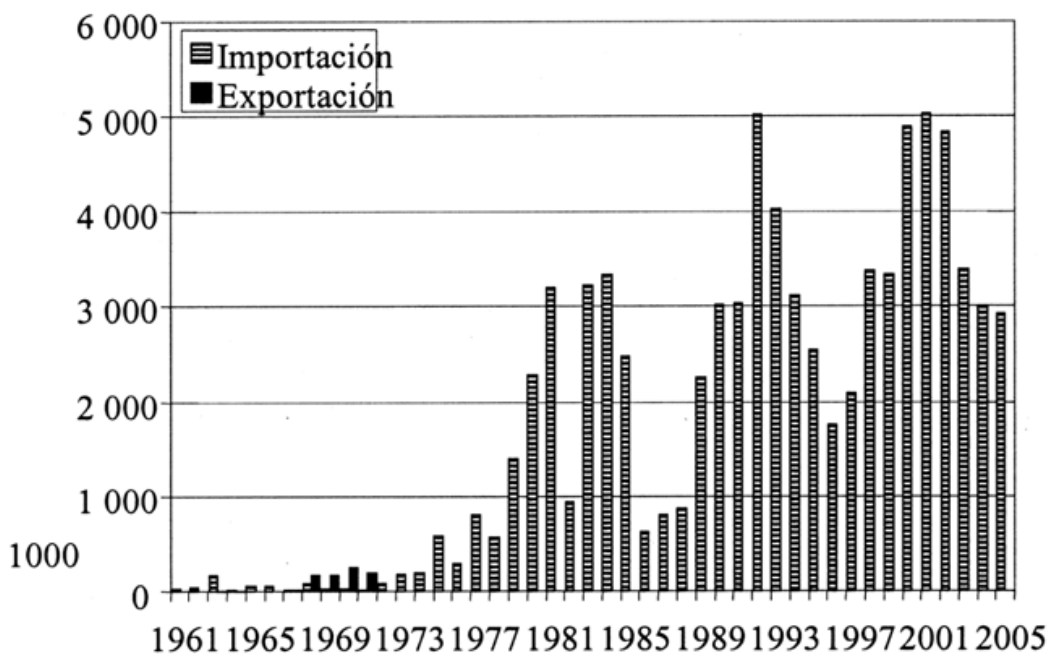

Gráfica 2. México. Evolución de las importaciones y exportaciones de sorgo, 1961-2005 (1 000 ton). Fuente: elaboración propia con base en USDA/FAS, 2006. 


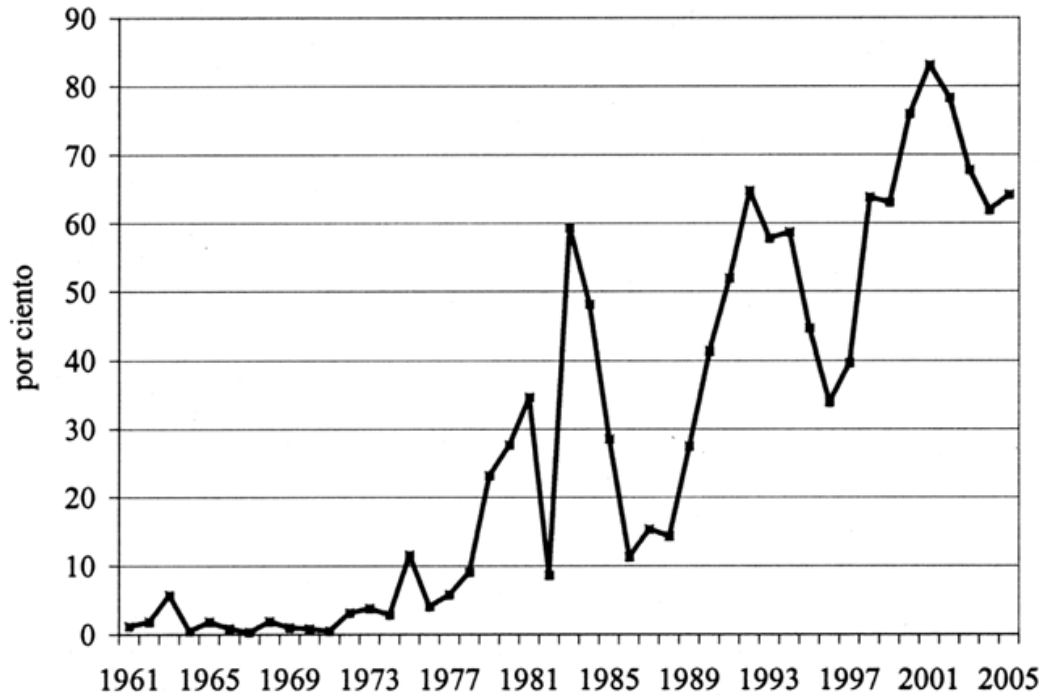

Gráfica 3. Estados Unidos. Participación de la exportación de sorgo a México en el total exportado, 19612005 (por ciento).

Fuente: elaboración propia con base en USDA/FAS, 2006.

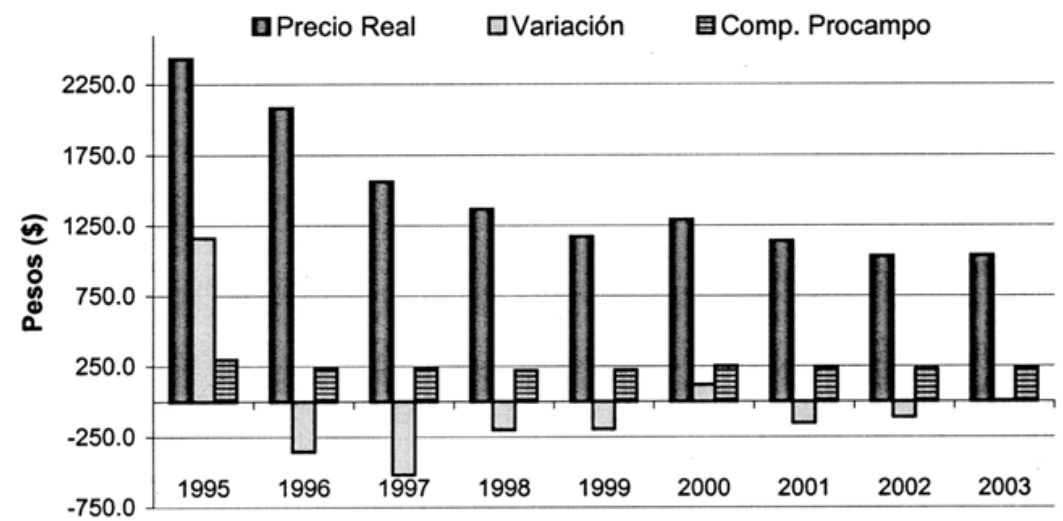

Gráfica 4. Sorgo. Precio real, variación y subsidio real de PROCAMPO por tonelada, 1995-2003 (\$/t) Fuente: elaboración propia con base en Precio Real de 2003 y con base en datos del Tercer Informe de Gobierno, 2003. Presidencia de la República, Tercer Informe de Gobierno. Anexo estadístico, crecimiento con calidad, 2004, http://tercer.informe.presidencia.gob.mx/index.php? idseccion=8". 
El porcentaje de sorgo importado de los Estados Unidos ha aumentado; por ejemplo, durante los años sesenta y setenta el porcentaje de las exportaciones de ese país a México era de $5.40 \%$ respecto al total exportado por ese país, pero desde 1986 hasta que se firma el Tratado de Libre Comercio de América del Norte (TLCAN) el promedio de este porcentaje ascendió a 34.76\%, y después de la firma hasta el 2005 se incrementó a 61.25\% (Gráfica 3 ). De acuerdo con las proyecciones del modelo de estimación, ${ }^{3}$ el consumo para el periodo 2005-2010 se ubicará en un máximo, en 2006, de 11282000 de toneladas, la producción tendrá una tasa media de crecimiento de $6.0 \%$ y en promedio se comprarán 3785.71 miles de toneladas. Las proyecciones estiman que México seguirá importando $60 \%$ de su demanda. De 2005 al 2010, México le comprará a Estados Unidos aproximadamente 73\% de su oferta exportable de sorgo.

Por otro lado, el precio real del sorgo, año base $2003,{ }^{4}$ en el periodo 1994-2003 presenta una tasa decreciente absoluta de -18\% y тсMA de -2\%, al pasar de \$1 272.07 a \$1 035.00 por tonelada. El apoyo recibido de PROCAMPO también presenta una tasa decreciente media anual de $-2 \%$ al pasar de $\$ 1093.92$ a $\$ 905.00$ por hectárea. Si se relaciona el diferencial de precio real del sorgo anual y se compara con el apoyo otorgado por PROCAMPO por tonelada a nivel nacional, se tiene que para el año 1996 se presenta una pérdida de \$119.84, y de \$-283.67 para 1997; lo cual significa que el PROCAMPO no compensa la caída del precio real pagado al productor para estos años (Gráfica 4) y específicamente para el estado de Guanajuato, donde los rendimientos por hectárea son en promedio de $6.6 \mathrm{t}$, y la pérdida es mayor. Por ejemplo, para el año: 1996 la pérdida fue de \$-218.40; de \$-382.56 en 1997; de \$-71.58 en 1998; y de \$-66.67 para 1999.

\section{Principales estados productores}

En México han destacado por su volumen de producción histórica los estados de Tamaulipas, Guanajuato, Michoacán, Jalisco y Sonora. En 2003 estas entidades produjeron 84.8\% de la producción nacional de este grano (6,759 millones de toneladas), de la cual Tamaulipas aporta $40.1 \%$, Guanajuato $24.1 \%$, Michoacán $10.1 \%$, Jalisco $5.3 \%$, Sinaloa $5.2 \%$, y otras 24 entidades producen $15 \%$. La producción se realiza en dos ciclos al año; en el de otoñoinvierno (O-I) en el que Tamaulipas es el principal productor; en el de primavera-verano $(\mathrm{P}-\mathrm{V})$ sobresale Guanajuato. La producción de Tamaulipas y Guanajuato ha tenido una

3 Para la determinación de las proyecciones de sorgo se consideró la información existente (USDA, Baseline Projections, 2004). Se realizó el ajuste de modelos de estimación econométricos para la producción e inventarios. El modelo que mejor predice es de tipo senosoidal; el modelo con los parámetros estimados respectivos es Producción Est. $=7332.8013+3325.2764 \operatorname{Cos}(0.3208$ Año 13.2723) y para predicción de los inventarios es Inventarios, Est. $=675.1436+427.2418$ Cos (0.6847Año 25.0127).

4 Fórmula para cambiar la base de una serie histórica: $\operatorname{IPP}_{\text {Base nueva }=}\left(\operatorname{IPP}_{\text {Base anterior }} / \mathrm{IIP}_{\text {Año base }}\right) * 100$.

\section{DeSarrollo}




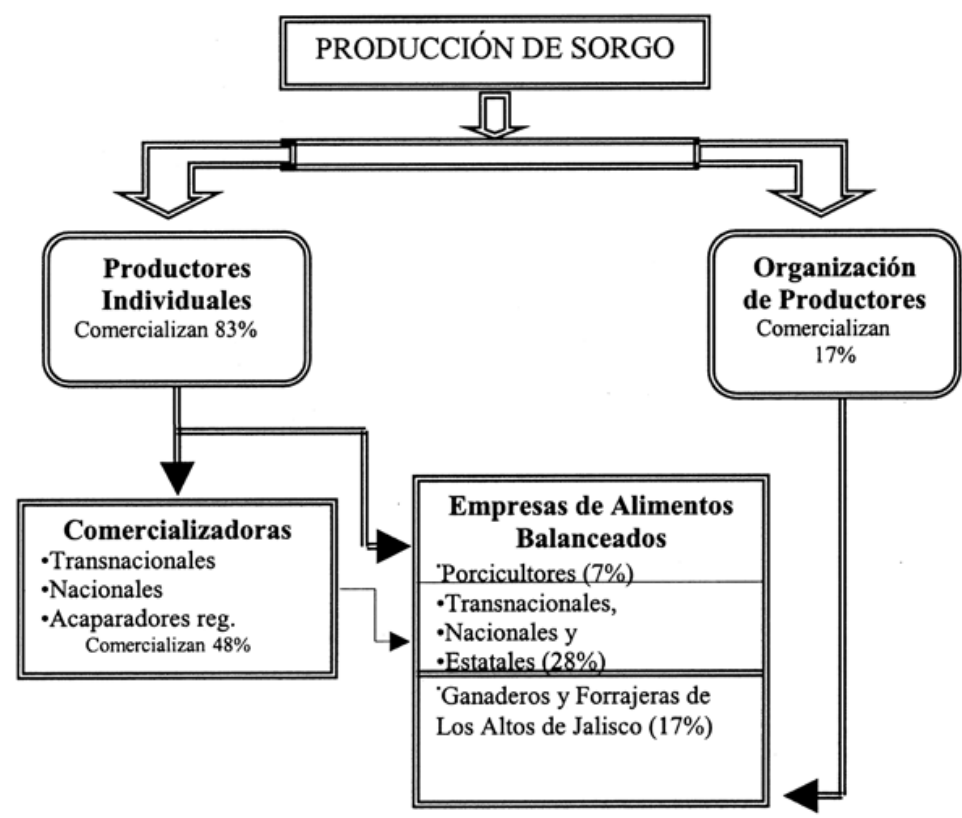

Gráfica 5. Guanajuato. Relaciones de comercialización del sorgo.

Fuente: elaboración propia con base en información de trabajo de campo en 2004.

tasa de crecimiento media anual en el periodo $1980-2003$ de $-0.10 \%$ y $2.4 \%$ respectivamente (SAGARPA/SIACON, 2004). En superficie sembrada y cosechada, Tamaulipas ocupa el primer lugar; en el periodo 1980-2002 ésta pasó de 649137 a 1050590 ha, lo que representa un crecimiento absoluto de $61.8 \%$; mientras que en Guanajuato, que ocupa el segundo lugar, presentó en este mismo periodo una tasa de crecimiento de $23.48 \%$, al pasar de 254618 a 283968 ha. En cuanto a los rendimientos de producción para el año 2003 Guanajuato registró $6.39 \mathrm{t} \mathrm{ha}^{-1}$ y Tamaulipas $3.3 \mathrm{t} \mathrm{ha}^{-1}$ (SAGARPA/SIACON, 2004).

\section{El sorgo en Guanajuato}

Los principales granos que se cultivan en Guanajuato son: sorgo, trigo, cebada y maíz, en los cuales el estado participa con $20.7 \%, 16.8 \%, 21.8 \%$ y $3.0 \%$ respectivamente del total de la producción nacional (SAGAR, 2000). La superficie de riego y temporal del cultivo del sorgo es de $57.5 \%$ y $42.2 \%$ respectivamente. La producción de sorgo en Guanajuato se concentra en diez de los 46 municipios, que aportan 77\% de la producción estatal; éstos se localizan en el sureste del estado (Gráfica 5).

La producción de sorgo en Guanajuato mostró un comportamiento dinámico en el periodo 1980 -2002, con una TCMA de $2.28 \%$ y una tasa absoluta de $60.75 \%$, al pasar de 975,091 toneladas a 1629 432. En este periodo la producción más baja se presentó en 1993, con 722095 t y la mayor se alcanzó en 1990, con 1691242 t. 


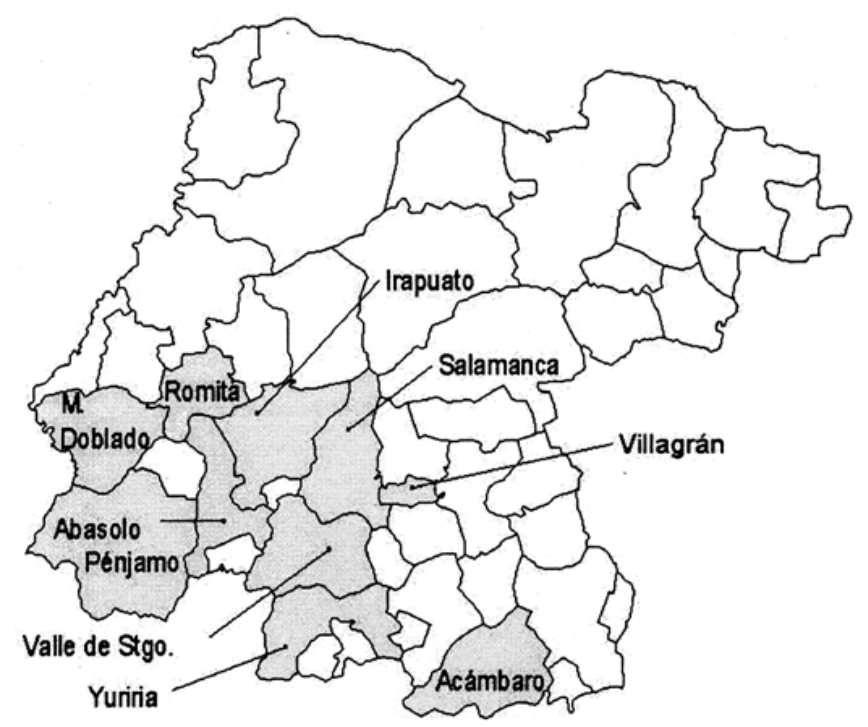

Mapa 1. Guanajuato. Municipios con mayor producción de sorgo (2002).

Fuente: Elaboración propia con datos de INEGI, 2003.

La superficie sembrada de sorgo para el periodo 1980-2003 presenta una TCMA de $0.14 \%$ al pasar de 454618 ha a 246744 ha, en tanto que la TCMA de la superficie cosechada es de $0.54 \%$, al pasar de 217795 ha 245386 ha (SAgARPa/SIACON, 2004). Este cultivo ocupa el $25 \%$ del total estatal de ambas superficies, con lo cual se ubica en segundo lugar después del maíz. Es notable en este cultivo una mayor eficiencia, ya que en el periodo 1980-2002 los rendimientos se incrementaron de 4.5\% t/ha a 6.7\% (SAGARPA/SIACON, 2004).

\section{Comercialización del sorgo en Guanajuato}

En la cadena de comercialización de sorgo figuran los productores, los comercializadores y los consumidores. Los productores ${ }^{5}$ venden el grano a diversos comercializadores entre los cuales están: empresas comercializadoras, industrias de alimentos balanceados, asociaciones agrícolas y porcicultores (para el 2003 se registraron 26869 productores de sorgo en el Programa de Apoyos Directos al Campo, con un promedio de superficie sembrada de $5.5 \mathrm{ha}$ ). No todo lo que se produce se comercializa a través de los canales reconocidos. De la producción total estatal registrada (1 500000 t) se sabe que de 400000 a 500000 t se comercializan a través de los otros instrumentos de venta.

5 De acuerdo con el censo ejidal de 2001, las unidades de producción rural en Guanajuato son 146 533, de las cuales 90233 (4.96\% del total nacional) son ejidales; 53 794, privadas y mixtas, 2506 (INEGI, 2004). La superficie total dedicada a la agricultura es de 1997229166 ha; 89.62\% corresponde a unidades mayores de 5 ha y $10.39 \%$ a unidades de producción hasta de 5 ha.

\section{DeSarrollo}


Cuadro 1

Guanajuato. Empresas comercializadoras, acopiadoras e importadoras de sorgo

\begin{tabular}{|c|c|c|c|c|c|}
\hline Empresa & Acopiadora & Comercial. & Importadora & $\begin{array}{c}\text { Alimentos } \\
\text { balanceado }\end{array}$ & Ubicación \\
\hline \multicolumn{6}{|l|}{ Trasnacionales } \\
\hline Cargill, S.A. de C.V. & Sí & Sí & Sí & No & Irapuato \\
\hline Mercograin S.A. de C.V. & Sí & Sí & Sí & No & Irapuato-Sal. \\
\hline Intergrain & Sí & Sí & Sí & No & Celaya \\
\hline Grain Encilares & Sí & Sí & $\mathrm{v}$ & No & Celaya \\
\hline Purina, S.A. C. V. & Sí & No & Sí & Sí & Salamanca \\
\hline Malta Clayton, S.A de C.V. & Sí & No & Sí & Sí & Villagran \\
\hline \multicolumn{6}{|l|}{ Nacionales } \\
\hline ALBAMEX, S.A de C.V. & Sí & No & Sí & Sí & Villagran \\
\hline La Hacienda, S.A de C.V. & No & No & Sí & Sí & Celaya \\
\hline \multicolumn{6}{|l|}{ Multiservicios 2001, } \\
\hline S.A de C.V ( Nutres) & Sí & Sí & Sí & $P$ & Manuel D. \\
\hline \multicolumn{6}{|l|}{ Estatales } \\
\hline Unión R.Ganadera & Sí & No & No & Sí & Irapuato \\
\hline ALBASA, S. A. C.V & Sí & No & n.d & Sí & Salamanca \\
\hline Mágnum, S.A. de C.V & Sí & No & Sí & Sí & Irapuato \\
\hline ALBACEL, S.A. C.V & Sí & No & n.d & Sí & Celaya \\
\hline ALBAPESA, S.A de C.V & Sí & No & Sí & Sí & Penjamo \\
\hline Organizaciones de produc. & Sí & Sí & No & No & \\
\hline Acaparadores & Sí & No & n.d & n.d & \\
\hline Porcicultores & Sí & No & n.d & Sí & \\
\hline
\end{tabular}

Fuente: elaboración propia con base en fase de campo.

Los comercializadores de sorgo se pueden dividir principalmente en: empresas trasnacionales y regionales (acaparadores y organizaciones de productores), ubicadas en las principales zonas de producción, que presentan gran dinamismo en tiempos de cosecha. Las empresas trasnacionales y acopiadores regionales se caracterizan por tener una gran infraestructura para el almacenamiento del grano, que posteriormente comercializan con la industria de alimentos balanceados a nivel nacional. Existen tres comercializadoras ubicadas en Irapuato y Celaya (Cuadro 1) y al menos se estima seis acopiadores en los municipios de mayor producción estatal, que en conjunto comercializan aproximadamente $48 \%^{6}$ de la producción. Las organizaciones de productores acopian $17 \%$ y su destino principal son Los Altos de Jalisco (Gráfica 5). Es importante señalar que las organizaciones de productores están tomando gradualmente mayor importancia en el canal de comercialización de sorgo.

6 Cifras aproximadas, de acuerdo con los representantes de las organizaciones de productores en Guanajuato (fase de campo, septiembre 2004). Debido a su alto contenido de carbohidratos y valor energético, el sorgo en Guanajuato, como en todo el mundo, tiene una función importante dentro de la alimentación animal. Así, la demanda de sorgo en el estado obedece principalmente a la necesidad de la industria de alimentos instalada en la región. 
Los consumidores finales, destino principal de la producción de sorgo del estado, están representados por empresas de elaboración de alimentos balanceados, que son empresas internacionales, nacionales o regionales. Entre las primeras figuran Purina, S.A. C. V. y Malta Clayton, S.A de C.V., ubicadas en Salamanca y Villagrán respectivamente. Las nacionales son Alimentos Balanceados de México (ALBAMEX), La Hacienda, y Multiservicios 2001. Entre las regionales que abastecen la mayor demanda local están la Unión Regional Ganadera, Magnum y Alimentos Balanceados de Pénjamo, que representan una seria competencia con las nacionales a nivel estatal, pues acopian $28 \%$ de la producción estatal. Los porcicultores acopian aproximadamente $7 \%$ de la producción.

Guanajuato y Tamaulipas tienen un papel importante en la producción. Sin embargo, la comercialización presenta condiciones diferentes en cada uno de los estados. Guanajuato tiene cercanía geográfica con los estados de mayor dinamismo en la fabricación de alimentos balanceados. Por ejemplo, a nivel nacional se registran 135 plantas de alimentos balanceados, de las cuales 49 están ubicadas en Jalisco, 10 en Guanajuato, 10 en Querétaro y 4 en Michoacán, que en conjunto concentran 54\% de este tipo de industrias (CANACINTRA, 2002: 52-62); de igual manera, se puede observar que estos estados son consumidores finales, ya que concentran el $26.51 \%$ de la producción pecuaria nacional (SAGARPA/SIACON, 2004). Por el contrario, el estado de Tamaulipas muestra problemas en la comercialización, debido a que las cosechas se concentran en los meses de junio y julio y en el sur de Texas comienza la cosecha un mes después de haber iniciado la de Tamaulipas, lo que constituye un factor importante de competencia; por otro lado, la producción de Tamaulipas está

alejada de las zonas de mayor consumo del país aproximadamente $850 \mathrm{~km}$, lo cual representa mayores costos de fletes y almacenamiento (SAGAR, 1999: 22).

\section{Programas de apoyo a la comercialización}

Antes de entrar a la descripción puntual de cada uno de los programas es importante señalar que en el periodo 1995-2003 el presupuesto orientado a los mismos presenta una tasa de crecimiento media anual de $23.59 \%$, al pasar de 806.56 millones de pesos a 4 393.21 millones, mientras que el presupuesto total destinado al sorgo en este periodo presenta una тСмA de $91.1 \%$, al pasar de 3.2383 millones de pesos a 577.800 millones (Gráfica 6). No obstante, sólo $6.7 \%$ del valor total de las importaciones de sorgo representa el apoyo a la comercialización de este grano para el periodo 1995-2001 (FAO, 2004 y Presidencia de la República, 2004).

En 2002, 83.73\% de los apoyos destinados a la comercialización fueron otorgados en mayor porcentaje a los estados de Sinaloa (33.90\%), Sonora (23.78\%), Tamaulipas (9.40\%), Baja California (6.10\%), Chihuahua (5.20\%), (Chiapas 3.22\%) y Guanajuato (2.13\%). Para 2003 Sinaloa recibió $21.23 \%$, Sonora el $12.66 \%$, Tamaulipas $17.16 \%$ y Guanajuato $2.31 \%$. De los 577.8 millones de pesos destinados al sorgo en el 2003, el estado de

\section{DeSarrollo}




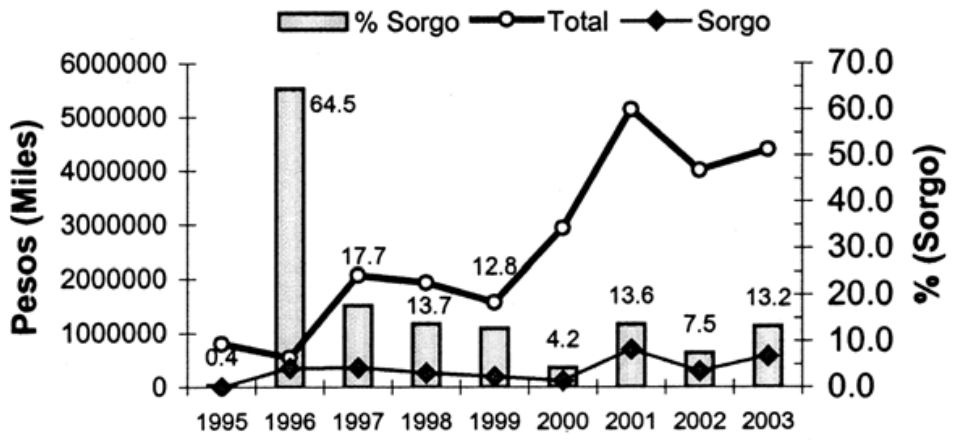

Año

Gráfica 6. Presupuesto destinado a Programas de Apoyos Directos a la Comercialización y Desarrollo de Mercados Regionales (1995-2003)

Fuente: elaboración propia con base en datos del Tercer Informe de Gobierno (Anexo Estadístico), 2004.

Cuadro 2

Volúmenes y montos de apoyo a los estados con mayor participación en los programas a la comercialización, 2002-2003

\begin{tabular}{llrrrr} 
Año & \multicolumn{1}{c}{$\begin{array}{c}\text { Volumen } \\
\text { (toneladas) }\end{array}$} & $\begin{array}{c}\text { Monto } \\
\text { (miles de pesos) }\end{array}$ & $\begin{array}{c}\text { Volumen } \\
(\%)\end{array}$ & $\begin{array}{c}\text { Monto } \\
(\%)\end{array}$ \\
\hline 2002 & Sinalidad & 4665786.80 & 1505898.70 & 26.66 & 33.90 \\
& Sonora & 3256506.30 & 1055894.51 & 18.60 & 23.78 \\
& Tamaulipas & 1844247.00 & 417796.66 & 10.53 & 9.40 \\
& Baja California & 718501.80 & 271078.96 & 4.08 & 6.10 \\
& Chihuahua & 895108.20 & 233471.96 & 5.10 & 5.20 \\
& Chiapas & 594748.00 & 143288.97 & 3.38 & 3.22 \\
& Guanajuato & 518651.60 & 93786.57 & 2.96 & 2.13 \\
& N. León & 13506.00 & 2250.29 & 0.08 & 0.05 \\
& Total & 17567936.80 & 4440210.80 & 100.00 & 100.00 \\
& Sinaloa & 4085112.14 & 1351716.83 & 17.60 & 21.23 \\
& Tamaulipas & 5411081.97 & 1092799.35 & 23.31 & 17.16 \\
& Sonora & 2682380.08 & 806194.64 & 11.56 & 12.66 \\
& Guanajuato & 301337.63 & 147146.75 & 1.30 & 2.31 \\
& N. León & 168227.55 & 60353.35 & 0.72 & 0.95 \\
& Total & 23207140.34 & 6367569.84 & 100.00 & 100.00 \\
\hline
\end{tabular}

Fuente: elaboración propia con base en ASERCA, 2002 y 2003a/b.

Tamaulipas recibió $96.70 \%$, Nuevo León $2.00 \%$, Sinaloa $0.10 \%$ y Guanajuato $0.09 \%$ (Cuadro 2). 


\section{Programas que tienen relación con la comercialización de sorgo}

\section{Subprograma Apoyo Directo al Ingreso}

Este programa, de carácter nacional, sólo opera en los estados cuando los precios de los granos están por debajo del precio de objetivo. ${ }^{7}$ Tiene como objeto apoyar económicamente a los productores, en función del tamaño de su predio, cuando hay excedentes de granos con problemas de comercialización. En los ciclos P-V 2003 y O-I 2003-2004, los estados de mayor participación fueron: Jalisco, con 143204947 pesos (que representaron 27.9\% del monto total del programa, 523869970 pesos) destinados principalmente a maíz; Chiapas, con $\$ 105095399$ (que representan 20.1\%) a maíz, y Chihuahua, con \$53902 407 (que representan 10.3\%) a maíz; Sinaloa con \$46561 035 (que representa 8.8\%) a frijol, y para Guanajuato, con \$11 568529 (que representa 2.2\%) a maíz. Los apoyos directos a maíz fueron de 150 pesos por tonelada y se autorizaron 800000 t, aunque sólo se apoyaron 166000 t (ASERCA, 2004). Esta baja canalización de apoyo se debió principalmente, a que parte de la producción es para autoconsumo, a la escasa difusión del programa, y a la condición del productor a registrarse ante Hacienda para poder cobrar el apoyo.

En 2002, cuando se estableció un precio objetivo de 1270 pesos por tonelada de sorgo, Tamaulipas recibió 533267850 de pesos para un volumen de 1975066 t, que representó 98.05\% del monto total; a Sinaloa le correspondió 1.39\%, y a Nuevo León, $0.053 \%$. Guanajuato sólo participó en este subprograma en el ciclo de P-V de 2001 y recibió un apoyo directo al ingreso de 100 pesos por tonelada, para un total de $712628 \mathrm{t}$.

\section{Subprograma cobertura de precios}

Este subprograma fue creado en 1996 con el objetivo de establecer un precio piso, así como para otorgar certidumbre y mejorar la rentabilidad de las cosechas de ciertos productos agropecuarios (maíz, trigo, sorgo — vía maíz-, soya, algodón, café, cártamo, ganado vacuno en pie y ganado porcino en canal), mediante un esquema de cobertura de precio. Para tal efecto, se establecieron 2 tipos de cobertura: opción Put, para proteger la caída de los precios, y opción call, para proteger el alza de los precios. Este último instrumento se incorporó al subprograma en respuesta a la demanda de los productores de cubrir riesgos contra incrementos de los precios y con el objetivo adicional de fomentar la "agricultura por contrato" (Claridades Agropecuarias, 1999:18).

7 El apoyo complementario al ingreso se estima con base en: Apoyo complementario al ingreso = ingreso objetivo mínimo precio de mercado. Los granos apoyados son: maíz, trigo, sorgo, cártamo, canola, algodón, arroz, soya, triticale y trigo forrajero. Este programa hasta 2001 canalizaba los apoyos a los productores a través de las comercializadoras; a partir de esa fecha se hacen los apoyos directamente a los productores.

\section{DeSarrollo}




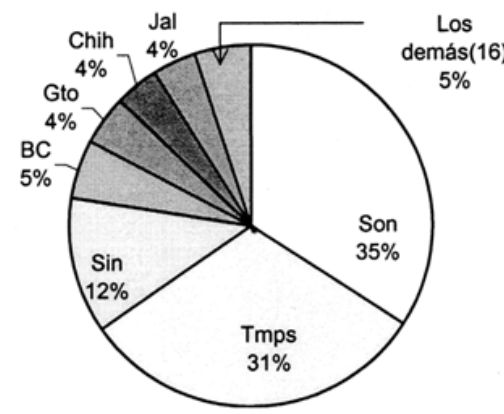

\begin{tabular}{|l|r|}
\multicolumn{2}{c|}{2003} \\
\hline Entidad & Importe (Pesos) \\
\hline Son & 59894373.30 \\
\hline Tmps & 37232970.15 \\
Sin & 8543392.76 \\
BC & 5175234.14 \\
Chih & 4751026.15 \\
NL & 2689503.35 \\
Mor & 1261174.14 \\
Gto & 768172.79 \\
Otros (4) & 377712538.88 \\
\hline
\end{tabular}

Gráfica 7. Participación porcentual de coberturas por entidad federativa: 1997-2003 e importe 2003. Fuente: $\quad$ ASERCA, 2004.

En 2004, ASERCA apoyó con 50\% del costo de la prima de ambas opciones, las cuales están establecidas en los lineamientos y mecanismos específicos de este subprograma. ASERCA cuenta también con una página de internet ( $w w w$.infoaserca.gob.mx), donde presenta diariamente los costos de las coberturas con información de las Bolsas de Valores de Chicago y Nueva York. ${ }^{8}$

En el periodo 1997-2003, los estados con mayor participación en este subprograma fueron: Sonora, con 34.3\% del total de las coberturas; Tamaulipas, 30.9\%; Sinaloa, 12.4\%, Baja California, $5.1 \%$, y Guanajuato, $4.4 \%$ (Gráfica 7). El presupuesto ejercido para 2003 en sorgo fue de 37.024 millones de pesos, con un total de 5,297 contratos, de los cuales Tamaulipas participó con $97.8 \%$ y Guanajuato con $2.1 \%$. Tal asimetría es asociada principalmente a la falta de liquidez del productor para el pago del costo de la prima y a las complicadas reglas de operación del programa. Es importante señalar que México, a nivel de Latinoamérica, es el principal país con primas subsidiadas, donde se cubren de 5 a 7 millones de toneladas anuales; esto es, aproximadamente $40 \%$ de la producción comerciable del país (ASERCA, 2004).

En este subprograma tienen gran importancia las organizaciones de productores, debido a que la unidad para comprar un cobertura opción Put es de 127 t; así, los productores individuales deben tener de 25-35 ha para cubrirla en producción, y 50\% del costo de la prima en dinero en efectivo para gestionar ante ASERCA la compra de la cobertura. Luego, si los productores no tienen predios de esas extensiones, deben organizarse para constituir oferta y obtener los beneficios del subprograma. De esta manera para un mayor porcentaje en la participación de coberturas de precios al sorgo, los productores guanajuatenses deben

8 Las opciones de maíz, trigo, soya, ganado porcino en canal y ganado vacuno en pie se colocan en la bolsa de valores Chicago ( Chicago Board of Trade, свот y Chicago Mercantil Exchange, cME), y las de algodón, café y jugo de naranja, en la de Nueva York (New York Board of Trade, NYвOT). Las coberturas de sorgo se realizan vía maíz y las de cártamo, vía soya o aceite de soya (Claridades Agropecuarias, 2003:48).

\section{DeSarrollo}


estar organizados tanto para producir como para comercializar, y buscar así los medios financieros para la adquisición de las coberturas.

\section{Subprograma de pignoración}

Con este subprograma se apoya a los productores organizados, para retirar y almacenar el grano cuando las condiciones del mercado no favorecen el precio, y para llevarlo luego al mercado cuando mejora el precio. ASERCA apoya con un porcentaje del costo de almacenamiento y del costo de la prima para cubrir lo pignorado de una posible baja de precio; para ello, las organizaciones deben contar con condiciones de infraestructura de almacenaje y así obtener certificados de depósito que puedan pignorar. La entidad que participa con el mayor porcentaje apoyado por este subprograma es Tamaulipas debido principalmente a los excedentes de producción que tiene y a su capacidad de almacenamiento; Guanajuato sólo participó en el ciclo P-V 2001 con 11 organizaciones de productores. Así, sólo se utilizó 83\% del total del volumen e importe (ASERCA, 2004). En 2004, ASERCA apoyó a las organizaciones de productores que hacen pignoración con el costo de la cobertura del total almacenado y los costos que implica el almacenamiento. Es importante señalar que tanto las que organizaciones de Tamaulipas como las de Guanajuato pignoran por su cuenta, ya que obtener el apoyo del gobierno estatal es difícil.

\section{d) Programa de Agricultura por Contrato}

Con el fin de fomentar la comercialización oportuna de las cosechas en las mejores condiciones para el productor y reducir la incertidumbre derivada de la volatilidad de los precios internacionales, ASERCA promovió, a partir de 1998, la celebración de contratos a término entre productores y compradores (SAGARPA, 2003: 33). ASERCA define agricultura por contrato como los "contratos de compra-venta entre productores y compradores de granos en los que se establece el producto a comercializar, variedad, especificaciones de calidad, volumen, precio o fórmula para determinar el mismo, lugar, fecha y cobertura determinada". ASERCA cubre 50\% del costo de la prima call para el productor y $50 \%$ del put para comprador, lo cual es considerado como un instrumento de regulación de mercado. Este esquema no se ha presentado para el cultivo del sorgo en Guanajuato, pero se ha aplicado en otros granos; por ejemplo, en 2000, el esquema fue establecido entre Agroindustrias Integradas del Centro (AGROICEN) y organizaciones de productores y productores individuales por 9000 hectáreas de maíz; Maseca, a mediados de los noventa, estableció contratos de compra-venta entre las organizaciones de productores y productores individuales por 50000 t de maíz; a partir de 1998, Cargill impulsa en Guanajuato y en otros estados un programa de agricultura por contrato para trigo de la variedad Eneida F94. Este programa se inició en unas 40 hectáreas de parcelas demostrativas, mediante

\section{DeSarrollo}


Cuadro 3

Guanajuato. Organizaciones de productores para comercialización

\begin{tabular}{|c|c|c|c|c|c|}
\hline Núm. & Municipio & $\begin{array}{l}\text { Año de } \\
\text { creación }\end{array}$ & $\begin{array}{c}\text { Número } \\
\text { de inte- } \\
\text { grantes } \\
\text { de } \\
2004\end{array}$ & $\begin{array}{l}\text { Infra- } \\
\text { estruc- } \\
\text { tura de } \\
\text { almace- } \\
\text { namiento }\end{array}$ & $\begin{array}{l}\text { Linea } \\
\text { de } \\
\text { finan } \\
\text { cia } \\
\text { miento }\end{array}$ \\
\hline \multicolumn{6}{|l|}{ Integradora del R. Lerma S. de R. L. de C. V. } \\
\hline 1 Unión y Progreso del Campo S.P.R. de R.L. & Pénjamo & 1998 & 65 & sí & sí \\
\hline 2 Productores de Pénjamo S.P.R. de R.L. & Abasolo & 1997 & 15 & proceso & no \\
\hline 3 Productores del B. Emiliano Zapata S.P.R. de R.L. & Pénjamo & 1999 & 165 & sí & no \\
\hline 4 Productores Unid. la Hacienda S.P.R. de R.L. & Pénjamo & 1999 & 14 & no & no \\
\hline 5 Ágroproductores el Chiflido S.P.R. de R.L. & Pénjamo & 2001 & 22 & no & no \\
\hline 6 Graneros Camacho, S.P.R. de R.L. & M. Doblado & 1999 & 48 & no & sí \\
\hline 7 Productores Unidos la Granjena S.P.R. de R.L. & Pénjamo & 1999 & 13 & no & no \\
\hline 8 Purisima de Ramírez S.P.R. de R.L. & Pénjamo & 2001 & 15 & no & no \\
\hline 9 Productores Asociados de Abasolo S.P.R. de R.L. & Abasolo & 2001 & 14 & no & no \\
\hline 10 Producctores A. de Maravatio. S.P.R de R. L. & Sn. Fco. del R. & 2004 & 30 & no & no \\
\hline 11 Produc. A de Maravatio Encinal. S.PR de R. L. & S. F. del R & 2004 & 21 & proceso & no \\
\hline \multicolumn{6}{|l|}{ Integradora Agrop. del B.S. de R. L. de. C.V. } \\
\hline 12 Bastíón del Granero del Bajío S.P.R. de R.L. & Jaral del Pr. & 1994 & 72 & sí & sí \\
\hline 13 Agroproductores de Yuriria S.P.R. de R.L. & Yuriria & 2002 & 86 & sí & no \\
\hline 14 Unión de Ejidos «16 de Abril» S.P.R. de R.L. & Valle. de Sant. & 1986 & 230 & sí & sí \\
\hline 15 Productores de S. Pedro Piedra Gorda S.P.R. de R.L. & Manuel D. & 1995 & 66 & no & no \\
\hline 16 Canovas, S.P.R. de R.L. & Sn. Fco. del R. & 1995 & 45 & proceso & no \\
\hline 17 Los Progresistas de Romita S.P.R. de R.L. & Romita & 1998 & 98 & no & no \\
\hline 18 Soc. Cooperativa de Huanímaro S.P.R. de R.L. & Huanímaro & 1984 & 106 & sí & sí \\
\hline
\end{tabular}

Fuente: elaboración propia con base en información de trabajo de campo, septiembre, 2004.

acuerdos entre productores individuales y organizaciones de productores (Steffen y Echánove, 2003: 132-139).

\section{Organización de productores para la comercialización}

Características de las organizaciones de productores

En Guanajuato existen aproximadamente 55 organizaciones de productores, pero sólo 18 de ellas están vinculadas a la operatividad de los subprogramas de comercialización. Existen dos integradoras que agrupan a estas 18 organizaciones, constituidas en Sociedades de Producción Rural de Responsabilidad Limitada, las cuales representan aproximadamente $10 \%$ del total de los productores. Los principales propósitos de las organizaciones son: a) la comercialización de granos básicos de los pequeños productores, socios y no socios, para disminuir el intermediarismo existente y obtener mayor ganancia en la venta del producto, b) la tramitación del crédito de la banca privada para cubrir el pago del grano, y c) gestionar los recursos de los programas de comercialización. Las organizaciones de 
Cuadro 4

Datos básicos de organizaciones según información de representantes de productores

\begin{tabular}{lcccc}
\hline \multicolumn{1}{c}{ Nombre de la organización } & $\begin{array}{c}\text { Año de } \\
\text { creación }\end{array}$ & $\begin{array}{c}\text { Número inicial } \\
\text { de integrantes }\end{array}$ & $\begin{array}{c}\text { Número de } \\
\text { integrantes 2004 }\end{array}$ & $\begin{array}{c}\text { Nivel escolar del } \\
\text { representante }\end{array}$ \\
\hline Bastión del Granero del Bajío, S.P.R. de R.L. & 1994 & 36 & 72 & Secundaria \\
Unión y Progreso del Campo, S.P.R de R.L. & 1998 & 28 & 65 & Secundaria \\
Graneros Camacho, S.P.R. de R.L. & 1999 & 11 & 48 & 1o. Secundaria \\
Productores de S. P. Piedra Gorda, S.P.R. de R.L. & 1995 & 22 & 66 & 1o. Primaria \\
Soc. Cooperativa de Huanímaro S.P.R. de R.L & 1999 & 35 & 106 & Primaria \\
\hline
\end{tabular}

Fuente: elaboración propia con base en información de trabajo de campo, septiembre 2004.

productores son relativamente recientes, la mayoría de ellas (89\%) tienen menos de catorce años y agrupan, en promedio, 62 productores (Cuadro 3).

Los representantes de organizaciones entrevistados se caracterizan por tener conocimiento de la problemática que enfrenta el campo; además, conocen y manejan bien el funcionamiento de los programas de comercialización, a diferencia de los productores independientes, que no tienen la información disponible. Considerando la información vertida por los representantes entrevistados, el número de integrantes de las organizaciones ha aumentado en $170 \%$ desde su creación a la actualidad, al pasar de 132 productores a 357, y presentan un nivel de escolaridad básico (Cuadro 4).

Variables importantes en la participación

a los apoyos a la comercialización

Se considera que Guanajuato no tiene problemas en la comercialización de los excedentes de sorgo, dada su ubicación geográfica en una región donde se concentra un número significativo de compradores, tanto de empresas de alimentos balanceados y forrajeras como porcicultores, etc. En cambio, Tamaulipas, por ubicarse a una mayor distancia de los centros de consumo y por la estacionalidad de la producción, presenta problemas en la comercialización.

En Guanajuato, la superficie promedio de las unidades de producción de sorgo es de 5.64 ha, mientras que en Tamaulipas es de 28.06 ha. El padrón de productores en aquel estado es de 26007 en tanto que en Tamaulipas es de 24 652. Esto en lo que toca a los 10 municipios de mayor producción de ambas entidades (PROCAMPO, 2003), donde la superficie sembrada es de 246744 ha y 1035486 respectivamente (SAGARPA/SIACON, 2004).

En el ciclo de producción P-V/2001 y O-I/2001-2002, ASERCA tiene registrada para apoyos a la comercialización de sorgo a 219 organizaciones en Tamaulipas y sólo 15 en Guanajuato. Por su parte, Servicios Integrales de Almacenamiento y Comercialización de México (SIACOMEX) tiene registradas para Tamaulipas 15 organizaciones de productores, con 11 almacenes acondicionados y una capacidad de almacenamiento de $168000 \mathrm{t}$; y en 
Cuadro 5

Tamaulipas y Guanajuato. Precios por tonelada del sorgo más apoyos a la comercialización

\begin{tabular}{lccccc}
\hline \multicolumn{1}{c}{ Año } & $\begin{array}{c}\text { Precio medio } \\
\text { rural sorgo }\end{array}$ & $\begin{array}{c}\text { Apoyo } \\
\text { PRoCAMPo }\end{array}$ & $\begin{array}{c}\text { Apoyo a } \\
\text { comercialización }\end{array}$ & $\begin{array}{c}\text { Precio al } \\
\text { productor } \\
\text { con apoyo }\end{array}$ & $\begin{array}{c}\text { Diferencia } \\
\text { de precios } \\
\text { Tamps.-Gto. }\end{array}$ \\
\hline Tamaulipas & & & & & \\
1998 & 954.4 & 240.7 & 161.1 & 1360.3 & \\
2000 & 1038.4 & 299.2 & 241.1 & 1578.7 & \\
2001 & 839.4 & 318.8 & 240.5 & 1398.7 & \\
2003 & 1268.3 & 248.1 & 210.1 & 1826.5 & \\
Guanajuato & & & & & \\
1998 & 1038.2 & 111.9 & 0.0 & 1149.0 & -211.00 \\
2000 & 1108.7 & 138.9 & 0.0 & 1247.6 & -96.30 \\
2001 & 1054.4 & 148.0 & 99.3 & 1301.7 & -283.47 \\
2003 & 1326.4 & 161.6 & 55.0 & 1543.0 & \\
\hline
\end{tabular}

Fuente: elaboración propia con base a Claridades Agropecuarias, 1999 y 2001; ASERCA, 2001 y 2003; SAGARPA, 2000, 2001 y 2003 y Presidencia de la República, 2004.

Guanajuato sólo registra a la integradora Agropecuaria del Bajío que participa con 6 almacenes ubicados en Valle de Santiago, pero sólo uno cuenta con condiciones de almacenamiento para $32000 \mathrm{t}$.

Ahora, sumando el precio medio rural de sorgo por tonelada, más apoyo PROCAMPO más apoyo a comercialización, se tiene que los precios de Tamaulipas son superiores a los de Guanajuato; en 1998, el precio para Tamaulipas fue de \$1 360.3 por tonelada y en Guanajuato de \$1 149.0, con un diferencial de -211.00; en 2000, el diferencial fue de 321.08; en 2001, de -96.30, y en 2003, de -283.47, lo que le da a Tamaulipas mayor posibilidad de inversión (Cuadro 5).

\section{La problemática de la organización en la comercialización}

Los principales problemas que enfrentan las organizaciones de productores son: la falta de recursos crediticios, de apoyo del gobierno local y de infraestructura para almacenar el grano. Entre las 18 organizaciones consideradas, sólo $27 \%$ cuenta con líneas de financiamiento, en cinco de las cuales el Estado participa con capital semilla, y 33\% cuenta con infraestructura para almacenar el grano con capacidad promedio de $25000 \mathrm{t}$.

Aunado a lo anterior, $100 \%$ de los representantes entrevistados considera que las intenciones de los programas son buenas, pero el acceso a ellos es difícil por el excesivo número de requisitos que implican las reglas de operación. Por otro lado, ASERCA ha respondido muy lentamente a la demanda de apoyos; y además, cuando los ha proporcionado, los recursos casi siempre han llegado con retraso; incluso se resiste a crear programas que incentiven el desarrollo de las organizaciones.

\section{DeSarrollo}




\section{Productores y la formación de organizaciones}

75\% de los representantes de ASERCA respondieron que los productores no participan en los apoyos a la comercialización, no porque ignoren la existencia y funcionamiento de los programas, sino porque se resisten a registrarse ante la Secretaría de Hacienda y Crédito Público (SHCP), que es uno de los requisitos para otorgar los apoyos. Esto constituye una barrera para el acceso de los productores que no están organizados a los programas. Sólo $25 \%$ de los productores entrevistados que no pertenecen a una organización dijo desconocer los programas a la comercialización.

\section{La participación del estado en los programas a la comercialización}

El gobierno estatal participa con las organizaciones de productores en la comercialización. A partir de 1996, cuando varias de estas organizaciones estaban trabajando con pérdidas, las que lograron sobrevivir lucharon para que el gobierno las apoyara con la capacitación en los programas a la comercialización y en capital semilla, que consistía en un complemento económico de 25-30\% a la organización para el pago total de la cosecha de los socios de la organización. Este esquema tuvo gran éxito en las organizaciones, pues les permitía capitalizarse. Sin embargo, en la actualidad el apoyo al capital semilla esta muy restringido; sólo $27 \%$ de las organizaciones cuentan con capital semilla.

En 2004 y 2005, en el estado de Guanajuato existía un fondo denominado Fideicomiso para el Fortalecimiento de los Procesos de Comercialización de Granos y Oleaginosas en Guanajuato (FICOMEG), que apoyaba a las organizaciones con capital semilla. En este fondo, las organizaciones presentan su proyecto para ser evaluadas y constituirse en candidatas a financiamiento. También existe el programa titulado Fortalecimiento de Mercados Agropecuarios, que apoya a las organizaciones con los costos de operación y financieros.

\section{Importancia de la organización en la comercialización}

Todos los funcionarios y representantes de organizaciones consideran a la organización de productores como un elemento clave para que los pequeños productores se fortalezcan y así puedan tener más probabilidades de acceso, entre otros beneficios, al crédito, a mayor participación en los programas de comercialización, a otros programas otorgados por el gobierno estatal, a seguridad en el pesaje y en el pago del grano, así como a tener mayor información de lo que está sucediendo en el sector agropecuario para la toma de decisiones.

De igual manera, las organizaciones tienen una importante presencia en los canales de comercialización del sorgo, debido a que funcionan gradualmente como un regulador de precios en la región, donde existe un alto grado de intermediarismo; así, los acaparadores se ven obligados a pagar el mismo precio del grano que las organizaciones.

\section{DeSarrollo}




\section{Conclusiones y recomendaciones}

México es el primer importador de sorgo a nivel mundial; Estados Unidos, su principal proveedor. Se estima que para 2010 México le comprará a ese país $73 \%$ de su oferta exportable, por lo que, de acuerdo con las condiciones que prevalecen en el mercado, México cada día está más cerca de perder totalmente su soberanía alimenticia en sorgo.

Al comparar el diferencial de precio real del sorgo anual con el apoyo otorgado por PROCAMPO por tonelada a nivel nacional, se tiene que para el año 1996 se presenta una pérdida de \$-119.84 y de \$-283.67 para 1997, lo cual significa que el PROCAMPO no compensa la caída del precio real pagado al productor para estos años. Para Guanajuato, donde los rendimientos por hectárea son en promedio de $6.6 \mathrm{t}$, la pérdida es mayor.

El mayor porcentaje de los apoyos a la comercialización de sorgo se destinan a Tamaulipas, debido principalmente a sus condiciones del mercado, número de organizaciones e infraestructura y almacenaje; por el contrario, la falta de recursos crediticios y la falta de infraestructura para almacenar el sorgo son dos limitantes que enfrentan las organizaciones de productores en Guanajuato. Aunado a ello, la resistencia del productor a registrarse ante Hacienda para poder cobrar el apoyo, la falta de liquidez del productor y las complicadas reglas que tienen los programa.

La política de comercialización no sólo debe orientarse a los mercados donde existen problemas de comercialización, sino también debe fortalecer la integración de las organizaciones de productores equitativamente y no favorecer solamente a las de mayor capacidad económica y de almacenaje. Los subprogramas deben ser diferenciados, con objetivos que concuerden con las limitantes para la comercialización que presente de cada región.

El estado de Guanajuato debe seguir impulsando económicamente al pequeño y mediano productor de sorgo en la formación de nuevas organizaciones y convencerlos de que es la opción más viable para seguir en el mercado. Por otra parte, las organizaciones deben responder a los estímulos económicos otorgados por el estado. Las organizaciones de productores para la comercialización deben tener un plan de negocios, objetivos muy claros, capacidad para definir hacia dónde y cómo ir, estar actualizadas, ser constantes, luchar por programas que les favorezcan, y de igual manera no descuidar los aspectos internos de la administración y de ejecución de los acuerdos.

\section{Bibliografía}

ASERCA, Programa de apoyos directos a la comercialización y desarrollo de mercados regionales, Resultados principales del ejercicio fiscal 2002, 1o. de enero al 31 de diciembre, pp. 76-129, http://www.infoaserca.gob.mx/programas/ informe_anual_2002b.Pdf

\section{Desararrollo}


- Mercado Internacional de sorgo, Apoyo y Servicios a la Comercialización Agropecuaria. Dirección General de Operaciones Financieras, 2003a, pp. 1-15, http://www.infoaserca.gob.mx/ analisis/sublistaanalisis.shtml

-, Programa de apoyos directos al productor por excedentes de comercialización para reconversión productiva, integración de cadenas agroalimentarias y atención a factores críticos, Informe del Segundo Trimestre del Ejercicio Fiscal 2003, México, 2003b, pp. 56.

_, Programa de apoyos directos al productor por excedente de comercialización para reconversión productiva, integración de cadenas agroalimentarias y atención a factores críticos, Informe del Segundo Trimestre del Ejercicio Fiscal 2004, http://www.infoaserca.gob.mx/ programas/DGPC-20040722_2.pdf

, "La producción de sorgo en México", en Claridades Agropecuarias, 1993, 2: 4-9.

, "Programas de apoyos a la comercialización del sorgo de Tamaulipas del ciclo otoño invierno 1992/93", en Claridades Agropecuarias, 1993b, 2: 16-20.

, "ASERCA y los apoyos a la comercialización de granos y oleaginosas", en Claridades Agropecuarias 1994, 12: 3-7.

,"El sorgo mexicano: Entre la autosuficiencia y la dependencia externa", en Claridades Agropecuarias, 1996, 4: 4-13.

, "1er. Aniversario", en Claridades Agropecuarias, 1994, 12: 4-5.

, "Agricultura General. $10^{\circ}$ Aniversario", en Claridades Agropecuarias, 2003, 121: 48-58.

, “ASERCA 1998. Principales Resultados", en Claridades Agropecuarias, octubre 1999, pp 18-19.

Asociación Nacional de Empresas Comercializadoras de Productores del Campo A.C. (ANEC), 2004. http://www.laneta.apc.org/anec/Index.HTM

Ayala, J. Instituciones y economía; una introducción al neoistitucionalismo económico, Fondo de Cultura Económica, México, 1999, 397 pp.

Barkin, D.; R. Batt y B. R. DeWalt, Alimentos versus forraje, la sustitución entre granos a escala mundial, Siglo XXI-UAM Xochimilco, México, 1991, 183 pp.

CANACINTRA, La industria alimenticia animal en México 2002, Sección de Fabricación de Alimentos Balanceados para Animales. México, 2002, 65 pp.

Grammont De. Hubert, C. (coordinador), Neoliberalismo y organización social en el campo mexicano, Plaza y Valdés-Universidad Nacional Autónoma de México, México, 1996, 486 pp.

Flores, M y F. Rello, Capital Social Rural. Experiencia de México y Centroamérica, UNAMCEPAL-Plaza y Valdés, México, 2002, 195pp.
Flores Verduzco, J. J, Integración económica al TLCAN y participación estatal en el sistema de innovación tecnológica en granos y oleaginosa en México, Plaza y Valdés-unam, México, 2003, 253 pp.

Gobierno de Guanajuato, Anuario Estadístico de Guanajuato 2002, Secretaría de Desarrollo, Instituto de Información para el Desarrollo-León, Guanajuato, México, 2003.

Gordillo, G., Alian De Janvry y Elizabeth Sadoulet, La segunda reforma agraria de México: respuesta de familias y comunidades, 1990-1994, Fondo de Cultura Económica, México, 1999, 248p.

Instituto Nacional de Estadística Geografía e Informática (INEGI), Anuario Estadístico por Entidad Guanajuato, Aguascalientes, Aguascalientes, México, 2003, 708pp.

INEGI, Resultados del VII Censo Ejidal 2001, 2004, http://www.inegi.gob.mx.

Instituto Tecnológico de Estudios Superiores de Monterrey. (ITESM), Sorgo, 2004, 36 pp., http:// www.qro.itesm.mx/agronomia2/extensivos/ CsorgoIndice.htm

Martínez B., E.; H. Salas Q., y S. Suárez P, La globalización del sistema lechero: Estructura productiva, desarrollo tecnológico y actores sociales, Instituto de Investigaciones Sociales de la Universidad Nacional Autónoma de México. México, 2003, 14 pp.

Muñoz R., Manrubio; J. Reyes Altamirano, V. Horacio Santoyo y J.J. Flores, Servicios para el desarrollo rural. Aprendiendo de lo que ya funciona, CiestAAM, UACH, México, 2003, 126 pp.

FAO, Macroeconomía y políticas agrícolas: Una guía metodológica, Materiales de capacitación para la planificación agrícola 39, Grupo de América Latina y el Caribe del Servicio de Políticas y Planificación. Roma, 1995, 95 pp.

Organización de las Naciones Unidas para la Agricultura y la Alimentación-Instituto Internacional de Investigación de Cultivos para las Zonas Tropicales Semiáridas (FAO-ICRISAT), La economía del sorgo y del mijo en el mundo: hechos, tendencias y perspectivas, 1997, $31 \mathrm{pp}$. http:/ www.fao.org/docrep/W1808s/W1808S00. htm

FAO, Statistical databases. Agriculture, 2004, http:// apps.fao.org/default.htm

Presidencia de la República, Tercer informe de gobierno. Anexo estadístico, crecimiento con calidad, 2004, http://tercerinforme.presidencia. gob.mx/index.php?idseccion $=8$ y http://quinto. informe.presidencia.gob.mx/index.php

Secretaría de Agricultura, Ganadería, Desarrollo Rural, Pesca y Alimentación (SAGARPA), Situación actual y perspectivas de la producción de sorgo en México 1992-2004, México, 2003,70 pp. http://www.siea.sagarpa.gob.mx/ ar_comdownload.html

\section{Desaurrollo}


Secretaría de Agricultura, Ganadería, Desarrollo Rural, Pesca y Alimentación (SAGARPA), Lineamientos especificos del subprograma de apoyos a la agricultura por contrato de maiz amarillo y sorgo, ciclo agrícola primavera-verano 2004, http://www.infoaserca.gob.mx/programas/ DGPC-20046181.pdf

Steffen, Christine y Flavia Echánove, Efectos de las políticas de ajuste estructurales en los productores de granos y hortalizas de Guanajuato, Plaza y Valdés-Universidad Autónoma Metropolitana, México, 2003, 151 pp.
SAGARPA, Sistema de Información Agropecuaria de Consulta (SIACON), Agrícola anuario dinámico. Servicio de Información y Estadística Agroalimentaria y Pesquera/sAGARPA, 2004, http:// www.siap.sagarpa.gob.mx/ar_comagri.html USDA/Foreign Agricultural Service (USDA/FAS), Production, supply \& distribution on line, custom query, 2006, http://www.fas.usda.gov/ $\mathrm{psd} / \mathrm{psdselection.asp}$

USDA, USDA baseline projections to 2013.2004, http:/ /usda.mannlib.cornell.edu/data-sets/baseline/ 2004/index.html

\section{Desarrollo}

